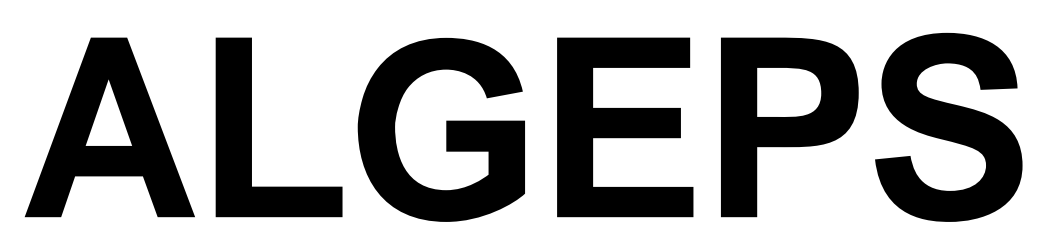

REVISTA DE GEOLOGIA, SĖRIE B no 625 - Abril del 2013

ISSN $1132-7014$

D.L.B. 28.178 - 92

14 pàgines

RECORREGUT GEOLÒGIC I MINERALÒGIC PER LES COMARQUES DE LA TERRA ALTA I DE LA RIBERA D'EBRE: DES DE GANDESA A MORA LA NOVA, MIRAVET, PINELL DE BRAI I A PRAT DE COMPTE

Josep M. Mata-Perelló i Joaquim Sanz Balagué 


\section{RECORREGUT GEOLÒGIC I MINERALÒGIC PER LES COMARQUES DE LA TERRA ALTA I DE LA RIBERA D'EBRE: DES DE GANDESA A MORA LA NOVA, MIRAVET, PINELL DE BRAI I A PRAT DE COMPTE}

Per Josep M. MATA-PERELLÓ i Joaquim SANZ BALAGUÉ

\section{ADVERTIMENTS PREVIS}

Com en altres recorreguts de RECERCA GEOLÒGICA I MINERALÒGICA ..., si es disposa del temps suficient, poden efectuar-se passant per totes les parades i filloles. En cas contrari, recomanem prescindir de les anomenades PARADES - CONDICIONALS.

També recomanem de cercar la informació més adient, sobre els trams a recórrer mitjançant camins de terra, o de pista.

Per d'altra banda, recomanem tenir una cura extrema de la NATURA, evitant qualsevol forma d'agressió sobre ella, o de fer-n'hi un mal ús del que en ofereix la nostra mare Terra.

\section{BREU INTRODUCCIÓ}

En aquesta ocasió, el recorregut del present itinerari discorrerà per una zona en la qual conflueixen tres unitats geològiques netament diferenciades: la Depressió Geològica de l'Ebre, la Serralada Prelitoral Catalana (integrant del Sistema Mediterrani) i la Serralada Ibèrica. Tot i així, els primers trams es faran per entre els afloraments cenozoics de la Depressió Geològica de l'Ebre i més concretament, per les immediacions de la denominada Zona de l'Avant - país plegat. Tot aquest recorregut es farà entre la població de Gandesa i la Venta de Camposines.

Tot seguit es tallaran breument els afloraments mesozoics de la Branca Externa de la Serralada Prelitoral Catalana, per arribar després a trobar de nou els afloraments cenozoics que reblen la Depressió de Mora (situades ambdues dintre del Sistema Mediterrani). Aquest recorregut s'efectuarà entre Camposines i les immediacions de la població de Miravet

Immediatament després, el recorregut transitarà per la Serralada Prelitoral Catalana (concretament per la denominada Branca Externa, de nou), per aquesta unitat geològica s'arribarà primer a les immediacions de Miravet, per on es tocarà la Serralada Prelitoral Catalana (però ara la seva Branca Interna). Tot i així, s’anirà circulant pel 
contacte entre aquesta i la ja esmentada Depressió de Mora, fins arribar a trobar la Serra de Cavalls - Serra de Pàndols, tot anant cap a Prat de Compte. Així, haurem tornat a penetrar a la Serralada Prelitoral Catalana (concretament per la denominada Branca Externa, per on ja hem circulat abans).

Per d'altra banda, el recorregut de l'itinerari, discorrerà fonamentalment per dues de les comarques que formen part de les Terres de l'Ebre o Regió de Tortosa, concretament per la del la Terra Alta i per la de la Ribera d’Ebre.

\section{OBJECTIUS FONAMENTALS D’AQUEST ITINERARI}

Els objectius fonamentals que es pretenen aconseguir en aquest itinerari, es poden concretar en els seguients aspectes generals:

1.- Observació i descripció dels materials terciaris (de l’Eocè i de l’Oligocè) de la Depressió Geològica de l'Ebre, que pertanyen majoritàriament al complex al-luvial de Gandesa - Horta de Sant Joan, que inclou, entre altres a la Formació Montsant i a la Formació Flix. Aquests materials, els anirem trobant als primers indrets del recorregut de l'itinerari, entre Gandesa, Corbera d'Ebre i la Venta de Camposines. També els trobarem entre Mora d'Ebre i Miravet; i entre aquest poble i la carretera de Pinell de Brai a Prats de Compte, tot formant part de la Depressió de Mora.

2.- Observació i descripció dels materials mesozoics (del Triàsic, del Juràssic i del Cretàcic), que constitueixen la Serralada Prelitoral del Sistema Mediterrani (a la seva Branca Externa). Aquests materials els trobarem entre la Venta de Camposines i les immediacions de Mora i a Miravet. I més endavant entre els voltants de la carretera del Pinell de Brai a Prat de Compte.

3.- Observació i descripció dels materials mesozoic (del Triàsic, del Juràssic i del Cretàcic), que constitueixen la Branca Interna de la Serralada Prelitoral del Sistema Mediterrani. Aquests materials els trobarem pels voltants de Miravet i de Pinell de Brai. de Mora.

4.- Observació dels mantells al·luvials quaternaris que reblen part de la Depressió

5.- Observació de les estructures locals d'aquests materials, al llarg del recorregut de l'itinerari, i de les relacions existents entre les dues unitats geològiques acabades d'esmentar. Així:

5A) de l'estructura de la Depressió Geològica de l'Ebre, que veurem als primers i als darrers trams del recorregut. Dintre d'aquesta unitat, veurem a distancia una important discordança progressiva.

5B) de l'estructura de Branca Externa de la Serralada Prelitoral Catalana (integrant del Sistema Mediterrani), que trobarem a diferents trams del recorregut. En molts indrets, aquests es troben prop de la seva Zona d'Enllaç amb el Sistema Ibèric.

5C) de la Depressió de Mora (ubicada entre les dues branques de la Serralada Prelitoral Catalana del Sistema Mediterrani), que trobarem entre Mora d'Ebre i la carretera que uneix el Pinell de Brai amb Gandesa. 
5D) de l'estructura de la Branca Interna de la Serralada Prelitoral Catalana (integrant del Sistema Mediterrani), que trobarem exclusivament pels voltants de les poblacions de Miravet i del Pinell de Brai.

6.- Observació de les explotacions mineres que es vagin trobant al llarg del recorregut de l'itinerari. Entre aquestes, cal fer esment de les relacionades amb les formacions argiloses, que trobarem a diversos indrets dels termes de Pinell de Brai, de Prat de Compte i d’Horta de Sant Joan, ubicades entre els materials del trànsit del Cretàcic Superior al Paleocè, sempre dintre de la comarca de la Terra Alta.

7.- Observació i anàlisi dels impactes produïts sobre el Medi Natural (i sobre el Medi Ambient), tant per les explotacions mineres anteriors, com per altres activitats humanes.

8.- Observació dels diferents indrets relacionats amb el Patrimoni Geològic $i$ Miner, que trobarem al llarg del recorregut. Dintre del Patrimoni Geològic, cal fer esment de la "discordança de Pinell de Brai" o "discordança de l'Estació", que trobarem prop de l'antiga Estació de Pinell de Brai.

\section{ANTECEDENTS BIBLIOGRÀFICS}

Pel que fa al recorregut del present itinerari, existeixen alguns antecedents molt propers, obra del mateix autor del present itinerari. Es tracta de MATA-PERELLÓ (1989, 1995, 1996b, 1997a, 1997, 2000a, 2000b, 2000c, 2001a, 2001b, 2001c, 2001d i 2006a i 2006b). Uns altres antecedents són: MATA-PERELLÓ i ARASA (2004 i 2007); i també MATA-PERELLÓ i MONTANÉ (2007), en uns itineraris força semblants al present.

Pel que fa a la descripció de les mineralitzacions d’aquesta comarca, farem esment d'un altre treball del mateix autor, de MATA-PERELLÓ (1991), relatiu a les mineralitzacions catalanes en general. Uns altres antecedents, cal situar-los en MATAPERELLÓ (1995a i 1995b), relatius als inventaris mineralògics de les comarques de la Terra Alta i del Matarranya.

I, finalment, pel que fa a l'estructura geològica de la zona per la qual discorre l'itinerari, farem esment dels treballs de GUIMERÂ et altri (1982) i de RIBA et altri (1976). També, i dintre d'aquest apartat, també farem esment de diversos treballs de l'IGME (1972). Tots ells són relatius a diversos fulls geològics corresponents als indrets per on passarà el recorregut de l'itinerari.

Tots aquests treballs referenciats, i d'altres, figuren esmentats per ordre alfabètic a l'apartat dedicat a la BIBLIOGRAFIA.

\section{RECORREGUT DE L'ITINERARI}

El recorregut de l'itinerari començarà dintre de la comarca de la Terra Alta, concretament pels voltants de la seva capital, la població de Gandesa, per on es farà la 
primera aturada. Tot seguit, el recorregut es dirigirà cap a Corbera d'Ebre i cap a Mora d'Ebre, passant de la comarca de la Terra Alta a la de la Ribera d'Ebre. En aquest tram es podran fer dues noves aturades.

Posteriorment, caldrà anar cap a Miravet. En aquest recorregut, efectuat íntegrament dintre de la comarca de la Ribera d'Ebre, efectuarem diverses aturades, pels voltants de Miravet..

Després, el recorregut es dirigirà cap a Pinell de Brai (entrant de nou a la Terra Alta), anant després en cap a Prat de Compte, per on finalitzarà el recorregut. En aquest tram es faran diverses aturades.

\section{DESCRIPCIÓ DE L'ITINERARI}

Com de costum, estructurarem el recorregut de l'itinerari en una sèrie de PARADES, que tot seguit anirem veient. En cada una d'aquestes aturades farem un breu comentari (geològic o mineralògic, segons s'escaigui).

Cada una d'aquestes parades tindrà un número, i un topònim representatiu. Per d'altra banda, s'indicarà el nom del poble més proper, el municipi al qual pertany l'indret, i la comarca on es troba situat. Per d'altra banda, també indicarem en cada cas, i entre parèntesi, el full topogràfic on es troba l'aturada.

Finalment, cal dir que el recorregut de l'itinerari s’inclourà dintre dels següents dos fulls, del "Mapa Topográfico Nacional", realitzats a l'escala 1:50.000 per 1'"Instituto Geográfico y Catastral": 470 (dit de Gandesa), 471 (dit de Mora d'Ebre) i 496 (dit d'Horta de Sant Joan).

Així doncs, la relació de parades ordenades, que composen aquest itinerari geològic i mineralògic, és el següent:

PARADA 1 - CONDICIONAL. ESTACIÓ D'AUTOBUSOS, (terme municipal de Gandesa, comarca de la Terra Alta). (Full 470).

El recorregut del present itinerari, s'iniciarà a la població de Gandesa, la capital de la comarca de la Terra Alta, iniciant-se a la moderna Estació d'Autobusos de la població, la qual es troba tot sortint cap a Corbera de Terra Alta, junt al costat de la carretera $N-420$.

Al respecte, cal dir que tant la població, com bona part del seu terme, es troba situat a la Depressió Geològica de 1'Ebre, molt a prop del contacte amb la Serralada Prelitoral, per la denominada Zona d'Enllaç amb el Sistema Ibèric. També cal recordar que l'esmentada serralada es troba al SE, al Sud i al SW d'on som, i es troba constituta pels relleus mesozoics de la Serra de Cavalls i els de la Serra de Pàndols. 
Així, els materials que es troben en aquest indret són terciaris, $i$ més concretament de l'Oligocè. Pertanyen, per d'altra banda, a la Formació Flix, que aquí forma part del Complex al·luvial de Gandesa - Horta de Sant Joan.

Els afloraments d'aquesta formació, es troben constituïts per nivells de calcolutites ocres $i$ de gresos, del mateix color, clarament continentals. Afloren amplament al Nord $i$ al $N E$ de Gandesa. Per d'altra banda, també cal dir que sovint, entre aquests materials es fan palesos paleocanals, com veurem més endavant prop de Bot.

PARADA 2. GUIXERA DE MORA, (terme municipal de Mora, comarca de la Ribera d'Ebre). (Full 470).

Des de la parada anterior, cal fer un recorregut tot seguint la carretera que es dirigeix cap a Corbera d'Ebre i cap a Mora d'Ebre. Per ella, després de fer un recorregut inferior als $8 \mathrm{Km}$, caldrà fer la present aturada, just d'on eix el camí que es dirigeix cap a una antiga guixera, situada a l'esquerra de la carretera.

En aquest recorregut, des de la parada anterior, s'han trobat inicialment els materials cenozoics que reblen la Depressió Geològica de l'Ebre, després de sobrepassar la Venta de Camposines, s' hauran començat a trobar afloraments dels materials mesozoics de la Serralada Prelitoral del Sistema Mediterrani. Tot i així, cap els voltants dels 2 Km, després de sobrepassar el trencall d'Ascó, s'han trobat uns afloraments dels nivells argilosos i guixosos que pertanyen al Triàsic Superior (al Keuper). Precisament, en aquest indret hi va haver una guixera, on es van explotar aquests materials guixosos. Actualment es troba totalment aturada i quasi perduda.

PARADA 3. EL CONGOST DE MIRAVET, (terme municipal de Miravet, comarca de la Ribera d’Ebre). (Full 471).

Des de la parada anterior cal acabar d'arribar a Mora d'Ebre. Després, ens caldrà continuar per la carretera que es dirigeix cap a Miravet. En arribar a aquest poble podem fer una nova aturada, a la vora del riu Ebre. Així, des de la parada anterior, haurem recorregut uns $10 \mathrm{Km}$ més.

En aquest recorregut, hem anat circulant inicialment pels materials esmentats a l'aturada anterior, els quals pertanyen a la Depressió de Mora, a través de la qual hem anat fent tot aquest tram del recorregut.

En arribar a l'indret de l'aturada ens haurem trobat amb l'aflorament dels materials mesozoics del Juràssic i del Cretàcic, de caràcter eminentment carbonatat. Aquests materials constitueixen els relleus sobre els quals s'assenta el Castell Templari de Miravet, al que anirem després. Cal dir que formen part del Bloc de Cardó; és a dir: de la Branca Interna de la Serralada Prelitoral Catalana. Precisament, el riu Ebre en travessar aquests materials (aigües avall del poble) ha configurar el Congost de Miravet, un dels indrets importants del nostre Patrimoni Geològic, que veurem millor des de la parada següent (FOTOGRAFÍA 1). 


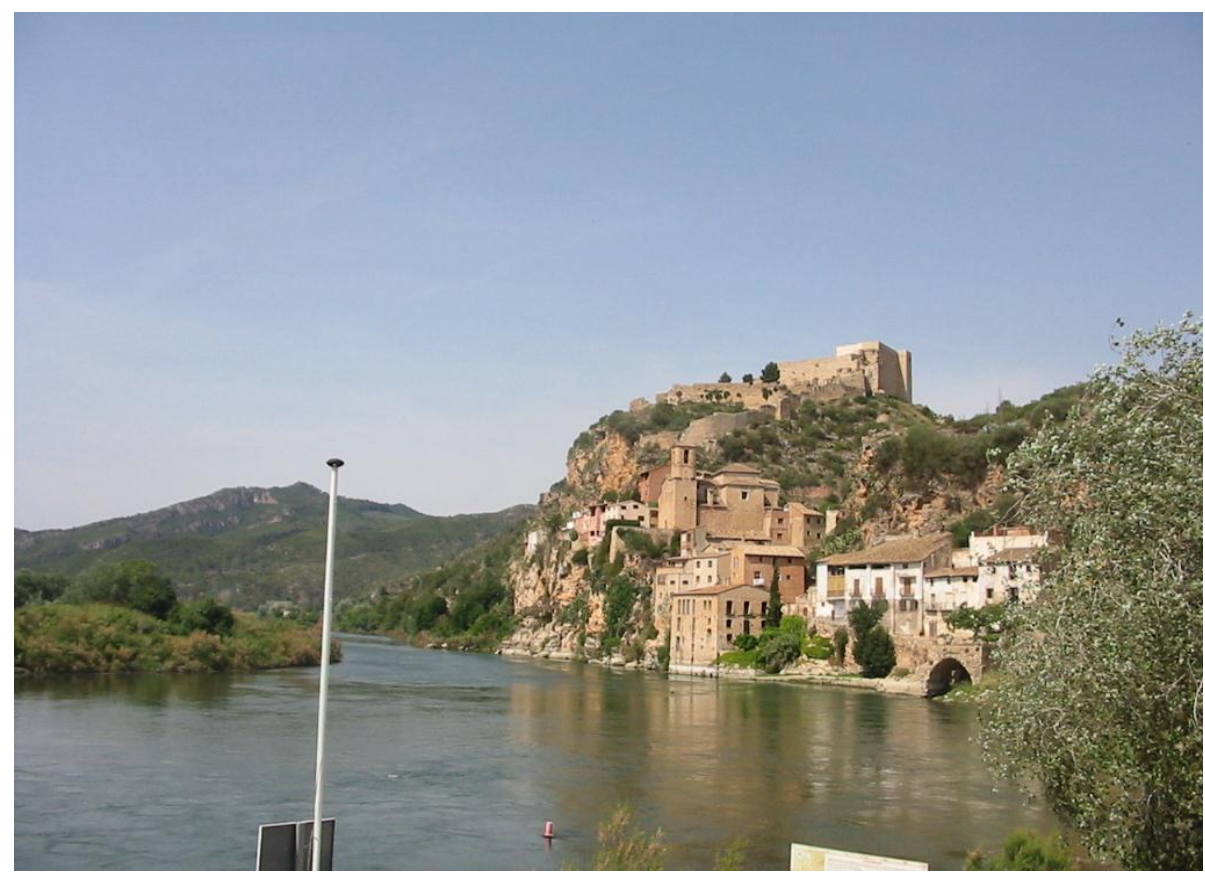

FOTOGRAFIA 1.

Aspecte de Miravet, sobre l'aflorament de roques carbonatades mesozoiques del Bloc de Card

PARADA 4. EL CASTELl DE MIRAVET, (terme municipal de Miravet, comarca de la Ribera d’Ebre). (Full 471).

Des de la parada anterior cal sobrepassar el poble de Miravet, des d'on ens caldrà seguir cap al Castell. En arribar-hi, caldrà fer una nova aturada, a quasi 1'5 km de l'anterior aturada.

En aquest recorregut, haurem anat trobant els materials mesozoics que constitueixen el turó on s'assenta el castell. Aquests materials mesozoics són roques carbonatades del Juràssic.

En arribar a quest indret, es pot gaudir d'un bon lloc d'observació de la Depressió de Mora. Aquest indret és complementari (i post) al que hem tingut a la PARADA 3). Com en aquell cas, també es poden observar els ventalls al-luvials quaternaris, que es situen formant ventalls (branques dels deltes) sobre els terrenys cenozoics que reblen l'esmentada depressió. Així, des d'aquí es pot veure perfectament el que es situa a llevant de Ginestar, prop de la Rambla del Compte.

També, des d'aquest lloc, mirant cap al Sud, es pot veure com el riu s'encaixa entre els materials mesozoics del Bloc de Cardó (de la Branca Interna de la Serralada Prelitoral Catalana), tot formant el denominat Congost de Miravet.

Per d'altra banda, es pot veure com en encaixar-se el riu abandona el primitiu curs, que anava de Rasquera al Perelló. Així, mirant cap al SE, es pot veure una extensa i ampla vall, situada entre la Serra de Tivissa i el Bloc de Cardó, per bon suposem que passava el vell riu Ebre, abans d'encaixar-se pel congost que ara veiem al Sud. 
Per d'altra banda, des d'aquest indret, es pot gaudir d'una bona visió del riu Ebre (FOTOGRAFIA 2).

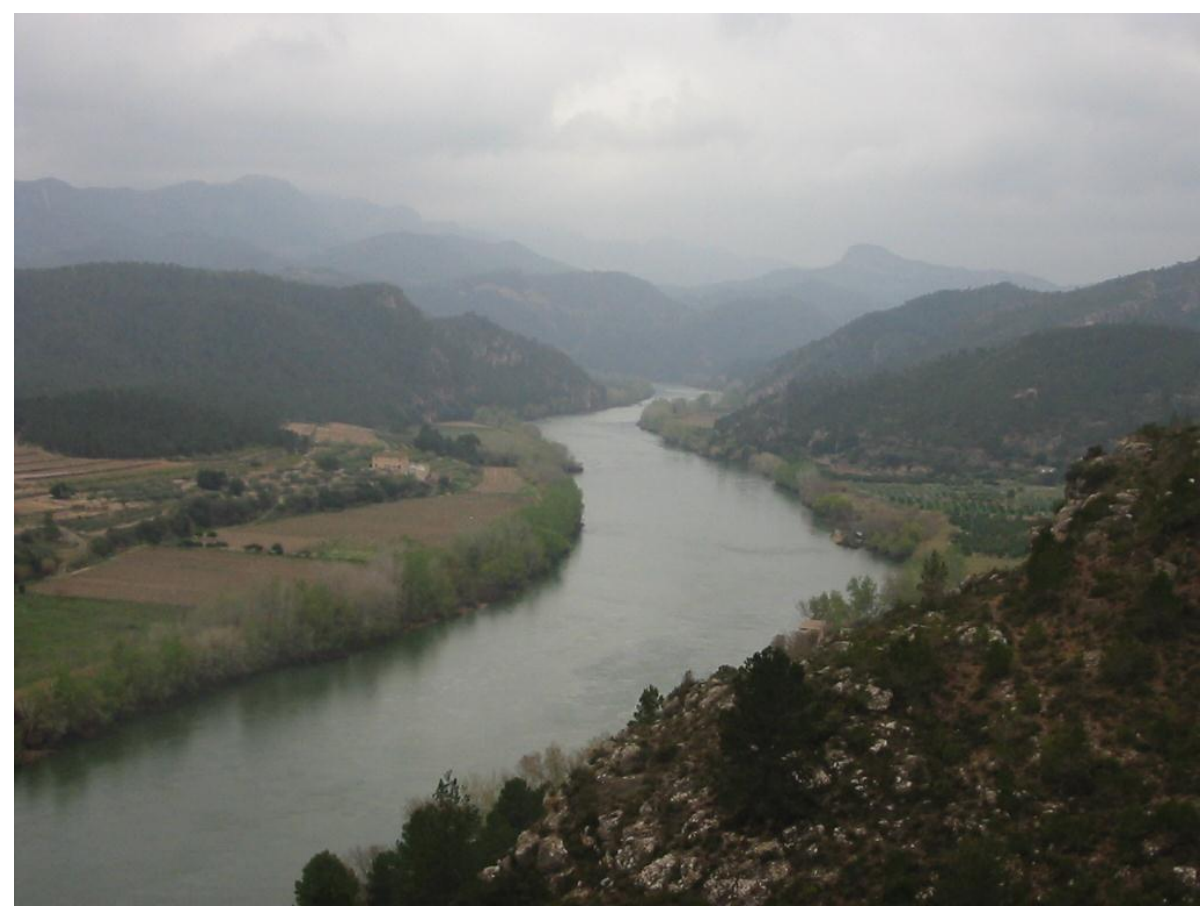

FOTOGRAFIA 2

El riu Ebre, aigües avall de Miravet, tot constituint el Congost de Miravet

\section{PARADA 5 - CONDICIONAL. LA PEDRERA DEL CASTELL,} CARRETERA A PINELL DE BRAI, (terme municipal de Miravet, comarca de la Ribera d'Ebre). (Full 470).

Des de la parada anterior, caldrà retornar cap a Miravet. Poc abans d'arribar-hi, es veurà una pedrera a l'esquerra de la carretera, on farem una nova aturada, si s'escau, a quasi $1 \mathrm{Km}$ de la parada anterior.

En aquest curt recorregut, hem anat trobant els materials mesozoics esmentats a la parada anterior. Precisament, en aquest lloc hi va haver-hi una pedrera, que va aprofitar aquests materials, possiblement per a ésser emprats per a la construcció del Castell.

PARADA 6 - CONDICIONAL. CRUÏLLA DE CARRETERES DEL PINELL DE BRAI, (terme municipal del Pinell de Brai, comarca de la Terra Alta). (Full 470).

Després de fer l'aturada anterior, cal sortir de Miravet per la carretera local (la T-324, que més endavant es converteix en la N-230c), per tal d'acabar d'arribar a Pinell de Brai, població que es troba la plenament ubicada dintre de la Depressió de Mora, ben prop de la denominada Zona de l'Avant-pais Plegat. La present aturada, si s'escau, 
caldrà fer-la prop del poble, just a la Cruïlla de Carreteres Estació, tocant a la carretera que es dirigeix cap al mateix poble. Així, des de la parada anterior, haurem recorregut uns $11 \mathrm{Km}$ més.

En aquest recorregut, haurem anat trobant els materials cenozoics que reblen la Depressió de Mora, on estem ara situats. Tot i així, haurem anat circulant per prop del contacte entre aquesta depressió i la Branca Interna de la Serralada Prelitoral Catalana, que es situa al Sud $i$ al SE d'on ara som.

En aquest indret es troben uns materials que pertanyen a la Formació Flix, $i$ es troben constituïts per trams materials gresencs $i$ calcolutítics ocres.

\section{PARADA 7. VOLTANTS DE L'ANTIGA ESTACIÓ DE LA RENFE DE PINELL DE BRAI, Km 13’3 DE LA CARRETERA N-230b, (terme municipal de Pinell de Brai, comarca de la Terra Alta). (Full 496).}

Després de fer la parada anterior, cal agafar l'antiga carretera $\mathrm{N}-230 \mathrm{~b}$, per tal d'anar cap a ponent. Així, en arribar a les immediacions de la vella Estació de la RENFE de Pinell de Brai (ja totalment abandonada), farem la primera aturada d'aquest itinerari, després d'haver recorregut uns $5 \mathrm{Km}$ des del Pinell i de la parada anterior.

En aquest recorregut, s' ha anat transitant per entre els afloraments cenozoics de la Depressió de Mora, encara que sempre molt a prop dels afloraments cretàcics i juràssics de la Serralada Prelitoral Catalana.

Per d'altra banda, en aquest indret de l'aturada hi ha un a clara discordança entre uns nivells eocènics (amb gresos i conglomerats) i uns altres afloraments cenozoics, en aquest cas de l'Oligocè (amb nivells de conglomerats), els quals cobreixen als anteriors.

Un esquema d'aquesta discordança (que sovint es coneix com a discordança de l'Estació de Pinell de Brai), és el següent:

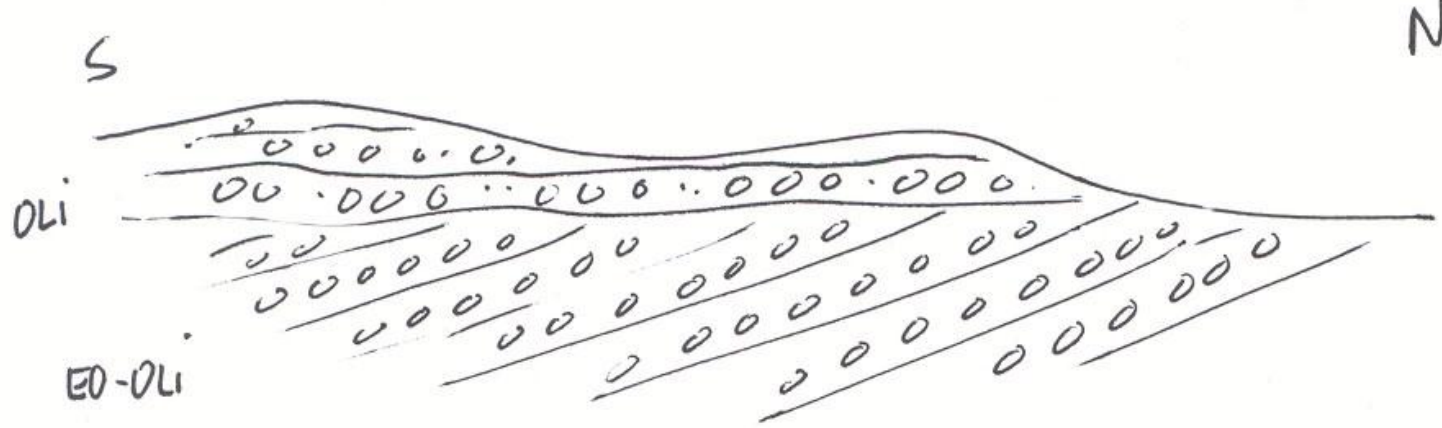

Es de destacar l'existència d'una coveta situada just al contacte acabat d'esmentar, per sobre de la carretera. Aquesta s'ha originat en circular les aigües entre els conglomerats subhoritzontals (força permeables), i en no poder fer-ho entre els materials subjacents, més impermeables. Tot això, es pot veure a la FOTOGRAFIA 3 


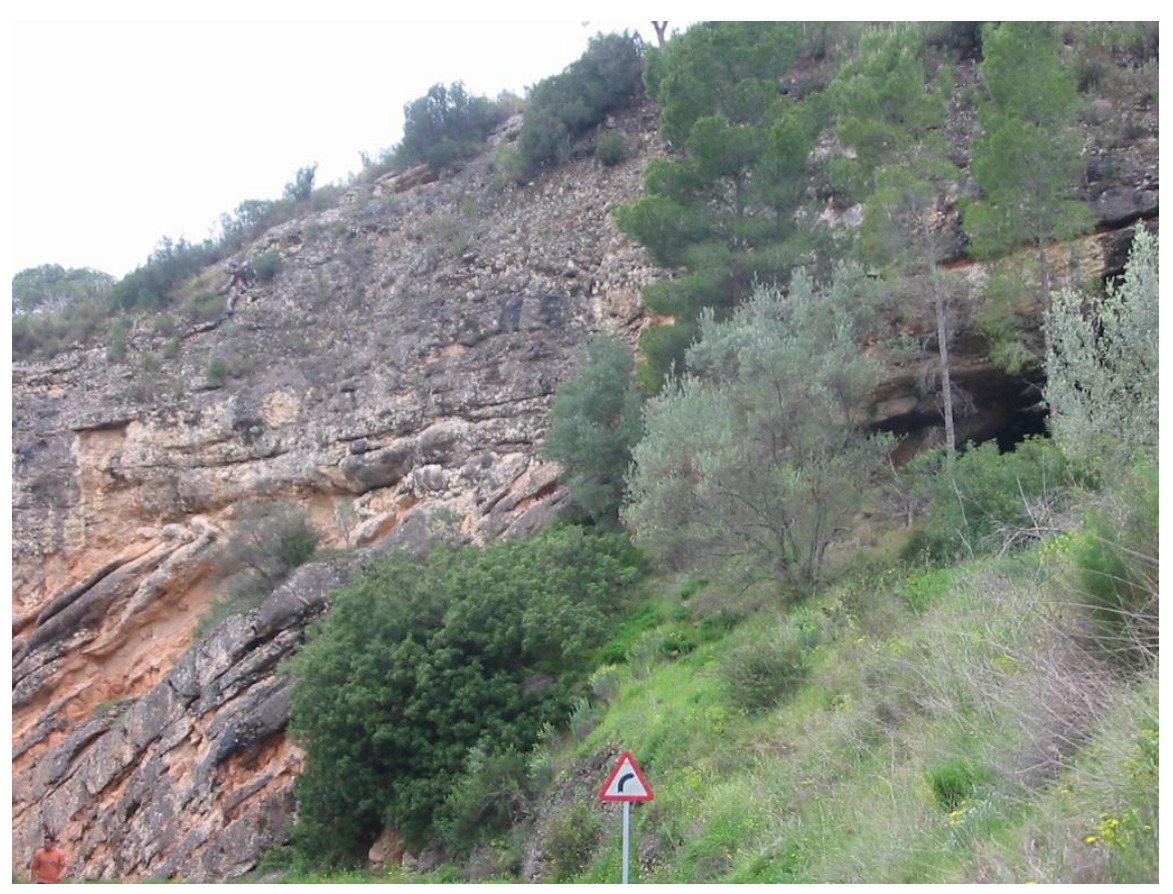

FOTOGRAFIA 3

Un aspecte de la Discordança de Pinell de Brai

PARADA 8. EXPLOTACIONS LUTÍTIQUES DEL SOLÀ D’ARGILARS, Kms 14-15`2 DE LA CARRETERA N-230b, (termes municipals de Pinell de Brai i de Prat de Compte, comarca de la Terra Alta). (Full 496).

Després de fer la parada anterior, cal fer un breu recorregut per l'antiga carretera $\mathrm{N}-230$, tot anant cap a ponent. En arribar al trencall que es dirigeix cap a les explotacions lutítiques del Solà d'Argilars, caldrà agafar-ho, fent en aquest indret, quasi a la vora de la carretera, la present aturada, després de recórrer uns 3'5 Km des de la parada anterior.

En aquest recorregut, hem abandonat la Depressió de Mora, i ens hem introduït a la Serralada Prelitoral Catalana, on ara ens trobem situats. Així, en aquest trajecte, hem anat trobant afloraments dels materials mesozoics del Juràssic i del Cretàcic; així com d'altres del Paleocè i de l'Eocè Inferior, els quals també formen part de l'esmentada serralada, en aquests indrets.

Aquí, hi ha unes interessants i nombroses explotacions dels trams argilosos del trànsit Cretàcic-Paleocè (concretament del Danià, equivalent al Garumnià pirinenc), les quals es reparteixen pels termes de Pinell de Brai i de Prat de Compte.

També es fàcil veure les instal-lacions d’una antiga bòbila, la qual aprofitava aquests materials. La bòbila es troba prop del túnel de l’antiga via de la RENFE.

Entre els materials argilosos explotats es troben diversos minerals com la CAOLINITA i la NACRITA. També hi són presents els òxids com l'ALUMOGEL i la BOEHMITA; així com el HEMATITES (que sovint els hi dona color rogenc) i el QUARS (arena). Un aspecte de les explotacions, es pot veure a la FOTOGRAFIA 4 


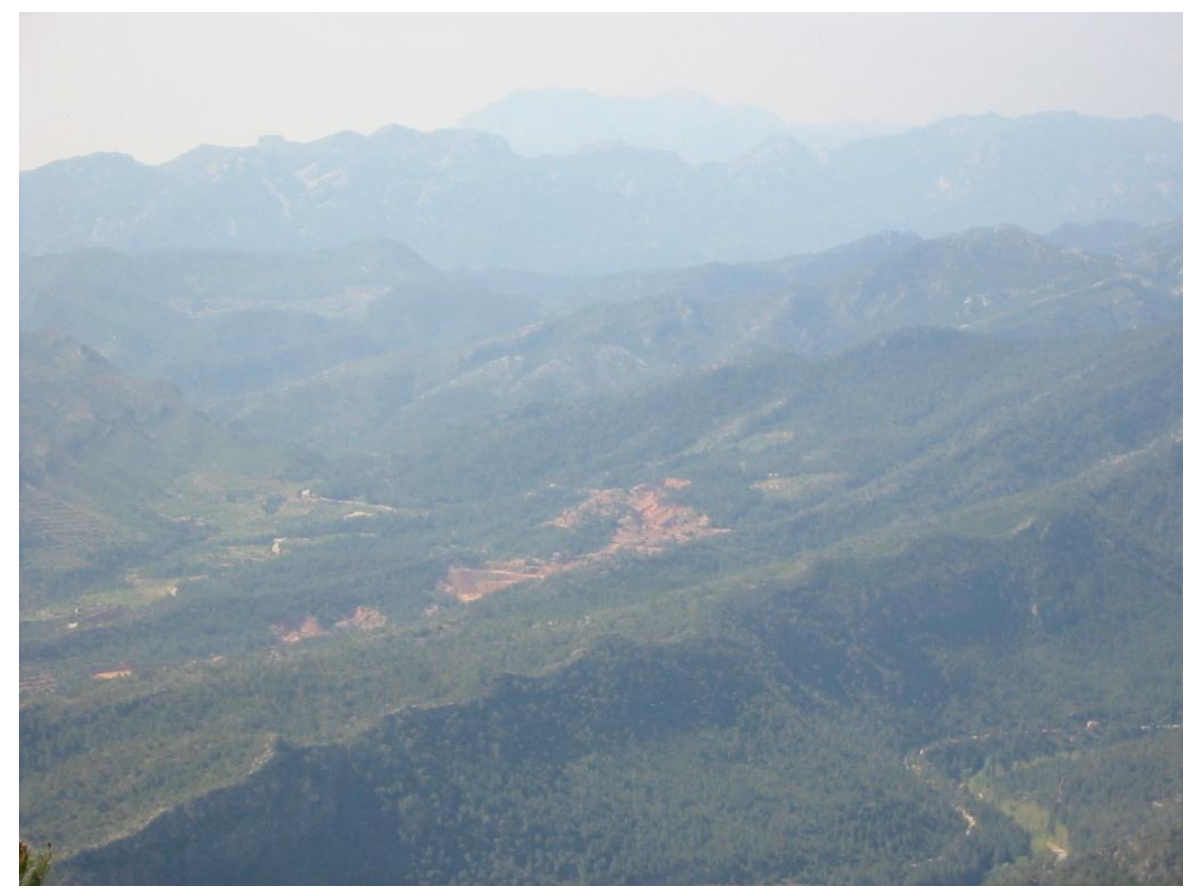

FOTOGRAFIA 4

Un aspecte de les explotacions des de la carretera de Gandesa a la Fontcalda

PARADA 9 - CONDICIONAL. IMMEDIACIONS DEL Km 17 DE LA CARRETERA N-230b, (terme municipal de Prat de Compte, comarca de la terra Alta). (Full 496).

Des de la parada anterior, cal retornar a la carretera, per tal de fer un petit recorregut per ella, arribant a les immediacions de l'antic Km 17 de la mateixa. En aquest lloc, a uns 3 de la parada anterior, farem la present.

En aquest recorregut, hem anat tallant els materials cretàcics $i$ cenozoics (paleocènics $i$ eocènics), amb un cabussament generalitzat cap al sud. Aquests darrers materials eocènics, són els que es troben on ara som.

Des d'aquest indret de l'aturada, mirant cap a llevant, cap a l'antiga estació, es pot veure clarament i a gran escala la denominada discordança de l'Estació de Pinell de Brai.

\section{PARADA 10 - CONDICIONAL. EXPLOTACIONS LUTÍTIQUES DE PRAT} DE COMPTE, (terme municipal de Prat de Compte, comarca de la Terra Alta). (Full 496).

Des de la parada anterior, cal continuar cap a ponent per la carretera $\mathrm{N}-230 \mathrm{~b}$, fins a trobar el trencall que es dirigeix cap a Prat de Compte (la carretera local T-333). Més endavant en arribar-hi, ens caldrà seguir per la carretera local T-330 (la qual se'n va cap a Horta de Sant Joan). Justament, des d'aquesta carretera, a la sortida de Prat de Compte, s'accedeix directament a les explotacions lutítiques del Barranc de la Xalamera, 
on farem la present aturada després de recórrer uns 7-8 Km des de la parada anterior, $i$ menys de 1'5 Km des del poble.

En aquest recorregut, hem tornat a tallar la sèrie, tot i que sovint hem transitat per prop del contacte Cretàcic-Paleocè. Així, sovint hem tallat afloraments dels materials mesozoics (del Triàsic, Juràssic i Cretàcic), així com dels cenozoics (del Burdigalià). Tots ells formen part de la Serralada Prelitoral Catalana.

En aquest lloc hi ha una explotació d'uns nivells lutítics, que pertanyen al trànsit del Cretàcic Superior a l'Eocè. Aquests materials pertanyen a la Serralada Prelitoral Catalana del Sistema Mediterrani, on ens trobem ara situats.

Entre aquests nivells, que aquí són molt sorrencs, es troba una abundant presència d'HEMATITES, i naturalment de CAOLINITA, que és el mineral explotat. També cal fer esment de la presència de QUARS (en forma d'arena).

Cal dir, per d'altra banda, que a més a més d'aquesta explotació de materials refractaris, n'existeixen d'altres, situades a diferents indrets del terme de Prat de Compte, i ubicades sempre entre aquests mateixos materials.

\section{EN AQUEST INDRET FINALITZA L'ITINERARI}

\section{REFERÈNCIES BIBLIOGRÀFIQUES}

GUIMERÀ, J. et altri (1992).- Geologia (II), Història Natural dels Països Catalans, Vol.2, 547 pag. Enciclopèdia Catalana, S.A. Barcelona

IGME (1974).- Mapa Geológico de España a escala 1:200.000. Sintesis de la Cartografia existente. Hoja y memória nº 41 (Tortosa). Inst. Geol. Min. España. Minist. Indústria. Madrid

MATA-PERELLÓ, J.M. (1989).- Una recerca mineralògica per les terres de 1'Ebre: del Matarranya al Priorat. But. Col. Ofi, de Doctors i Llicenciats, nº 67, 15pag. Barcelona

MATA-PERELLÓ, J.M. (1991).- Els Minerals de Catalunya. Arxius de la Secció de Ciències, t. XCIII, 442 pag. Institut d'Estudis Catalans. Barcelona

MATA-PERELLÓ, J.M. (1995a.- Apunts per a un itinerari geològico-mineralògic entre Gandesa (Terra Alta) i Fuentes de Ebro (Ribera Baja de Ebro), Inèdit, 12 p. Manresa

MATA-PERELLÓ, J.M. (1995b).- Inventari Mineralògic de la comarca de la Ribera d’Ebre, Terra Endins, n 9, 23 pag. Manresa

MATA-PERELLÓ, J.M. (1995c).- Inventari Mineralògic de la comarca de la Terra Alta, Terra Endins, $\mathrm{n}^{\circ}$ 10, 22 pag. Manresa

MATA-PERELLÓ, J.M. (1996).- Itinerari geològic i mineralògic entre Gandesa, la Font-calda i Vall-de roures. Inèdit., 12 pàgines. Manresa

MATA-PERELLÓ. J.M. (1997a).- Recerca geològica i mineralògica per les comarques de la Terra Alta i del Matarranya: des de Gandesa a Bot i Horta de Sant Joan, i des de Vall-de-roures a Fondespatlla. Inèdit, 17 pàg. Manresa 
MATA-PERELLÓ, J.M. (1997b).- Recerca geològica i mineralògica per les comarques del Priorat, de la Ribera d'Ebre, del Segrià i del Baix Cinca: des d'Ulldemolins a Flix i a Fraga. Inèdit, 14 pag. Manresa

MATA-PERELLÓ. J.M. (2000a).- Recerca geològica i mineralògica per les comarques de la Terra Alta i de la Ribera de 1'Ebre: des de Pinell de Brai i Prat de Compte a Gandesa i a Mora d'Ebre. Algeps, sèrie B, $\mathrm{n}^{\circ}$ 171, 14 pàg. Manresa

MATA-PERELLÓ. J.M. (2000b).- Recerca geològica i mineralògica per les comarques de la Terra Alta i del Matarranya: des de Gandesa a Vall-de-roures i a Fondespatlla. Algeps, sèrie B, nº 176, 18 pàg. Manresa

MATA-PERELLÓ, J.M. (2000c). - Recerca geològica i mineralògica per les comarques de la Ribera d’Ebre i del Priorat: des de Flix cap Ascó, el Molar i Mora. Inèdit. 11 pag. Manresa

MATA-PERELLÓ, J.M. (2001a). Recorregut de recerca geològica i mineralògica per les comarques del Baix Camp, de la Ribera d’Ebre i del Baix Ebre: des d'Hospitalet de 1'Infant al Perelló; i des de Rasquera a Mora la Nova i Ascó. Inèdit. 16 pag. Manresa

MATA-PERELLÓ. J.M. (2001b).- Recorregut de recerca geològica i mineralògica per les comarques de la Ribera d'Ebre i de la Terra Alta: des d'Ascó a Pinell de Brai, i des de Prat de Compte a Horta de Sant Joan, Inèdit, 18 pàg. Manresa

MATA-PERELLÓ. J.M. (2001c).- Recorregut de recerca geològica i mineralògica per les comarques de la Terra Alta i del Matarranya: des d’Horta de Sant Joan a Vall-de-roures i a Fontespatlla Inèdit, 18 pàg. Manresa

MATA-PERELLÓ. J.M. (2001d).- Recorreguts geològics i geonaturalistics pels Ports. Escola d'Estiu del Col.legi de Llicenciats, 75 pag. Manresa

MATA-PERELLÓ. J.M. (2006a).- Recorregut geològic i miner per les comarques de la Ribera d'Ebre i Terra Alta: des d’Ascó a Mora d’Ebre, Miravet, Pinell de Brai, a Prat de Compte i a Bot. Inèdit. 16 pag. Manresa

MATA-PERELLÓ. J.M. (2006b).- Recorregut geològic i mineralògic per les comarques de la Ribera d'Ebre i Terra Alta: des de Vinebre a Mora la Nova, Miravet, Pinell de Brai i a la Fontcalda. Inèdit, 12 pag. Manresa

MATA-PERELLÓ, J.M. i ARASA, A. (2004).- Recorregut geològic i miner per la comarca de la Terra Alta: des de Gandesa i el Pinell de Brai cap a Prat de Compte i Horta de Sant Joan. Inèdit, 12 pag. Manresa

MATA-PERELLÓ, J.M. i ARASA, A. (2007).- Recorregut geològic i miner per la comarca de la Terra Alta: des de Gandesa i el Pinell de Brai cap a Prat de Compte i cap a Horta de Sant Joan. Inèdit, 12 pag. Manresa

MATA-PERELLÓ, J.M. i MONTANÉ GARCÍA, P. (2007).- Recorregut geològic i miner per les comarques de la Terra Alta i de la Ribera d'Ebre: des de Gandesa a Mora la Nova, Miravet, Pinell de Brai i a la Fontcalda. Inèdit, 12 pag. Manresa

RIBA, O. et altri (1976).- Geografia Física dels Països Catalans, Edit. Ketres, 254 pàgines. Barcelona. 